Check for updates

Cite this: RSC Chem. Biol., 2021, 2,556

Received 8th December 2020,

Accepted 21st January 2021

DOI: $10.1039 / \mathrm{d} 0 \mathrm{cb} 00228 \mathrm{c}$

rsc.li/rsc-chembio

\section{Metathramycin, a new bioactive aureolic acid discovered by heterologous expression of a metagenome derived biosynthetic pathway $\dagger$}

\author{
Luke J. Stevenson, (D) abc Joe Bracegirdle, (D) bcd Liwei Liu, ${ }^{a}$ Abigail V. Sharrock, (D) abc \\ David F. Ackerley, (D) ${ }^{\text {abc }}$ Robert A. Keyzers (D) ${ }^{\text {bcd }}$ and Jeremy G. Owen (D) *abc
}

\begin{abstract}
Bacterial natural products have been a rich source of bioactive compounds for drug development, and advances in DNA sequencing, informatics and molecular biology have opened new avenues for their discovery. Here, we describe the isolation of an aureolic acid biosynthetic gene cluster from a metagenome library derived from a New Zealand soil sample. Heterologous expression of this pathway in Streptomyces albus resulted in the production and isolation of two new aureolic acid compounds, one of which (metathramycin, 6) possesses potent bioactivity against a human colon carcinoma cell line $\left(\mathrm{HCT}-116, \mathrm{IC}_{50}=14.6 \mathrm{nM}\right)$. As metathramycin was a minor constituent of the fermentation extract, its discovery relied on a combination of approaches including bioactivity guided fractionation, MS/MS characterisation and pathway engineering. This study not only demonstrates the presence of previously uncharacterised aureolic acids in the environment, but also the value of an integrated natural product discovery approach which may be generally applicable to low abundance bioactive metabolites.
\end{abstract}

\section{Introduction}

Aureolic acids are a family of glycosylated aromatic polyketides that have potent bioactivities against human cancer cells and Gram-positive bacteria. ${ }^{1,2}$ All naturally occurring aureolic acids have been discovered from soil or marine actinomycete bacteria, and the biosynthetic gene clusters (BGCs) for two of these have been described: mithramycin (Fig. 1, 1) from Streptomyces argillaceus, ${ }^{1,3}$ and chromomycin $\mathrm{A}_{3}$ (Fig. 1, 2) produced by Streptomyces griseus subsp. griseus. ${ }^{4}$ Although aureolic acids have been approved for clinical use (e.g. mithramycin for testicular carcinoma and myeloid leukemia), their clinical applications remain limited due to significant off target toxicity. ${ }^{5,6}$

The potent anticancer bioactivity of mithramycin and chromomycin $\mathrm{A}_{3}$ has fuelled a search for new congeners. The search for these mithramycin analogues ("mithralogs") has predominantly taken the form of gene knockout or combinatorial biosynthesis based on the known biosynthetic genes and pathways

\footnotetext{
${ }^{a}$ School of Biological Sciences, Victoria University of Wellington, Wellington, New Zealand. E-mail: jeremy.owen@vuw.ac.nz

${ }^{b}$ Maurice Wilkins Centre for Molecular Biodiscovery, New Zealand

${ }^{c}$ Centre for Biodiscovery, School of Biological Sciences, Victoria University of Wellington, Wellington, New Zealand

${ }^{d}$ School of Chemical and Physical Sciences, Victoria University of Wellington, Wellington, New Zealand

$\dagger$ Electronic supplementary information (ESI) available. See DOI: 10.1039/ docb00228c
}

for mithramycin and chromomycin $\mathrm{A}_{3}{ }^{6}$ There are two main regions of the compound structure that have been targeted for diversity generation. The first is the significant sugar decoration of the polyketide core (premithramycinone, Fig. 1, 3), which can be modified by deletion or complementation with different sugar biosynthesis pathways and/or glycosyltransferase enzymes Mtm/ CmmGI-GIV. ${ }^{7,8}$ The second is the aliphatic tail which is generated by oxidative cleavage of the fourth ring in the tetracyclic precursor (premithramycin B, Fig. 1, 4) by Mtm/CmmOIV, and subsequent sidechain reduction by $\mathrm{Mtm} / \mathrm{CmmW}$. Gene knockout of the sidechain reductase has been demonstrated to produce a set of analogue compounds with distinct toxicity profiles. ${ }^{2,4}$

Microbial natural products discovered via strain isolation and bioactivity guided fractionation have been a phenomenally rich source of medically relevant compounds. ${ }^{9}$ Another method for uncovering novel chemistry from microbes is the discovery of new biosynthetic pathways from environmental microbes. Gene-first natural product discovery by metagenomic analysis has produced numerous novel bioactive secondary metabolites in recent years, ${ }^{10-15}$ providing access to the biosynthetic capacity of microbes independent of our ability to culture these organisms. ${ }^{16-19}$ This approach has proven particularly fruitful when applied to aromatic polyketides, leading to the discovery of improved congeners of clinically relevant compounds. ${ }^{20}$ In this study, we constructed and screened a soil metagenome cosmid library for ketosynthase alpha $(\mathrm{KS} \alpha)$ bacterial type II polyketide genes. Sequencing of the recovered library cosmid 

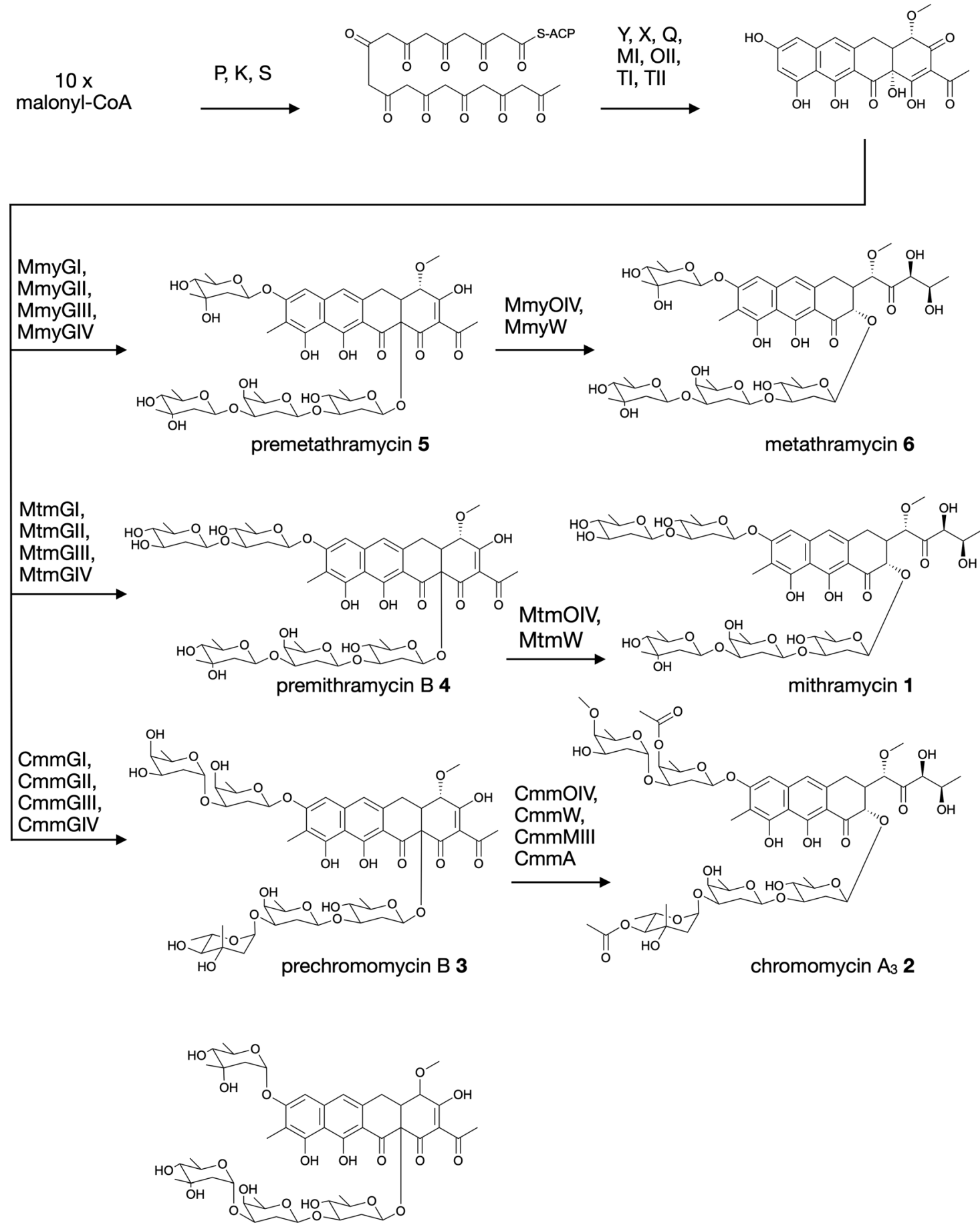

chromocyclomycin 7

Fig. 1 Biosynthesis of aureolic acids mithramycin and chromomycin $A_{3}$, and the structure of chromocyclomycin.

clones resulted in the partial sequence of an aureolic acid biosynthetic gene cluster with low sequence identity to previously reported clusters. Recovery and reconstitution of the full gene cluster from two overlapping cosmid clones permitted heterologous expression in Streptomyces albus, ultimately resulting in the discovery of two new aureolic acid compounds that we have named premetathramycin (Fig. 1, 5) and metathramycin (Fig. 1, 6).

\section{Results and discussion}

Discovery and recovery of novel gene cluster from a soil metagenomic library

Soil collected in Half Moon Bay, Kaikōura, New Zealand, was used as the source of microbial diversity to construct a metagenome library. High molecular weight environmental-DNA (eDNA) was extracted, purified, and cloned into the cosmid 
vector pWEB::tnc using in-house prepared lambda phage packaging extract. ${ }^{21,22}$ The resulting library of $>10$ million cosmid clones, each containing 30-40 kb of metagenome DNA, was arrayed over four 96 well plates. These arrayed wells were then screened by PCR with degenerate primers targeting bacterial KS $\alpha$ genes, ${ }^{23}$ using previously established serial dilution plating protocols. ${ }^{10}$

The resulting cosmid clones were pooled and sequenced as a single library (Illumina HiSeq, PE100 bp chemistry). Following assembly with SPAdes, ${ }^{24}$ contigs were matched to individual cosmid insert end sequences by Sanger sequencing, and the assembled metagenome insert sequences analysed with antiSMASH v4. ${ }^{25}$ One of the recovered cosmids had $68 \%$ gene cluster similarity by clusterBLAST to the aureolic acid pathway producing mithramycin and $58 \%$ to chromomycin $\mathrm{A}_{3}$. Notably, however, the individual amino acid sequences encoded by the genes in the partial gene cluster had a relatively low homology to the known aureolic acid biosynthesis pathways, and the gene arrangements were also unique. The recovered cosmid contained only a partial gene cluster sequence, as it was apparent that the $m t r X$ gene homologue involved in self resistance and DNA repair was truncated at the cosmid insert boundary. ${ }^{26}$ Other key resistance genes involved in compound efflux in mithramycin and chromomycin $\mathrm{A}_{3}$ pathways were not present in the recovered cosmid. ${ }^{27,28}$ Reconstitution of the biosynthetic pathway was achieved by re-screening the soil metagenome library using primers targeting each end of the initially recovered cosmid. ${ }^{29}$ Cosmids extending the recovered sequence in both directions were recovered, however only the sequence that complemented the truncated $m t r X$ homologue appeared to contain additional biosynthetic genes. Sequence data for the complete metathramycin BGC has been deposited in GenBank with the accession number MW512268.

The two cosmids containing putative biosynthetic genes were then used to construct a complete and contiguous biosynthetic pathway as a single BAC clone. This was achieved using a modified version of previously published protocols for transformation associated recombination (TAR) in yeast ${ }^{30}$ in which the insert sequences from the two cosmids were liberated from the pWEB::tnc vector using in vitro Cas9 digestion with sgRNA targeted to the vector edges. Double-stranded DNA breaks near assembly sites has been demonstrated to increase recombination frequency in TAR, ${ }^{31}$ and the use of targeted Cas9 digestion resulted in free DNA ends within 200 bp of recombination sites. TAR was performed in a previously described $S$. cerevisiae strain deficient in non-homologous end joining ${ }^{32}$ to reduce non-recombinant background colonies, and in a single transformation all emergent colonies (12) analysed tested positive for correct assembly with multiple PCR tests along the BGC length. The reconstituted BGC was then verified by DNA sequencing, and was annotated using results from antiSMASH analysis, as well as BLAST search comparisons of the encoded genes to mithramycin and chromomycin BGCs (Fig. 2A and Table 1). This gene cluster has been assigned the name metathramycin (MMY), as a reference to both the discovery of this gene cluster in a metagenome library, and the gene cluster level similarity to the mithramycin BGC (Table 2).

The metathramycin gene cluster has a length of $42302 \mathrm{bp}$, similar to mithramycin (42374 bp) and chromomycin $\mathrm{A}_{3}$ (42074 bp). Of the genes that were assigned to homologous functions, the mean percentage amino acid identity of the products was $60.7 \%$ to mithramycin and $52.7 \%$ to chromomycin $\mathrm{A}_{3}$. In general, the highest amino acid identities in the MIBiG database for most genes in the metathramycin pathway were with genes from the two aureolic acid gene clusters, however this was notably not the case for the first six enzyme functions (core polyketide biosynthesis by $\mathrm{P}, \mathrm{K}, \mathrm{S}$, and cyclisation/aromatisation by $\mathrm{X}, \mathrm{Y}$, and $\mathrm{Q}$ ). Only $\mathrm{Q}$ had its nearest homologue in chromomycin $\mathrm{A}_{3}$, while all other genes aligned to other, non aureolic acid type II PKS biosyntheses.
A.

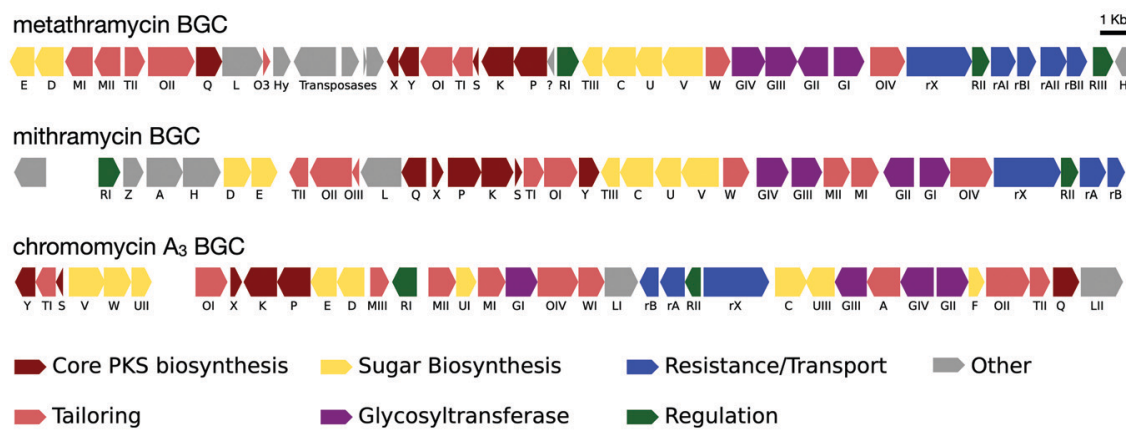

B.

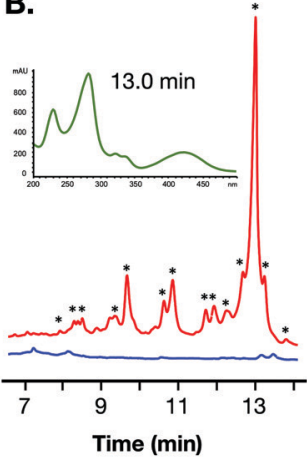

Fig. 2 Discovery and heterologous expression of an aureolic acid biosynthetic gene cluster from a soil metagenome library. (A) Comparison of our metagenome derived aureolic acid cluster (MMY cluster) to the known clusters for mithramycin and chromomycin $A_{3}$. Genes are coloured based on broad function classifications. Amino acid identities for alignments of homologous genes are provided in Table 1. (B) HPLC traces for extracts from S. albus harbouring the MMY biosynthetic gene cluster (S. albus::MMY, red) and an empty vector control (S. albus, blue). Metabolite peaks with the characteristic aureolic acid UV absorbance spectrum (inset, green) are indicated with an asterisk (*). Compound $\mathbf{5}$ is the major metabolite peak, with a retention time of $13 \mathrm{~min}$. Select minor metabolite peaks were identified by EIC of the LCMS trace; compound $\mathbf{6}$ is a minor metabolite with retention time $9.4 \mathrm{~min}, 4$-demethylpremithramycinone $7.3 \mathrm{~min}$ and premithramycinone (3) peak at $9.8 \mathrm{~min}$. The retention time on the reversed-phase $C_{18}$ column is shown on the $X$-axis, and absorbance at $420 \mathrm{~nm}$ on the $Y$-axis. 
Table 1 Gene cluster comparison of aureolic acid biosynthesis genes: homologous genes between the metathramycin (MMY), mithramycin (MTM) and chromomycin $\mathrm{A}_{3}(\mathrm{CMM})$ biosynthetic gene clusters are indicated, with percentage amino acid identities of Mmy proteins to Mtm and Cmy proteins, respectively

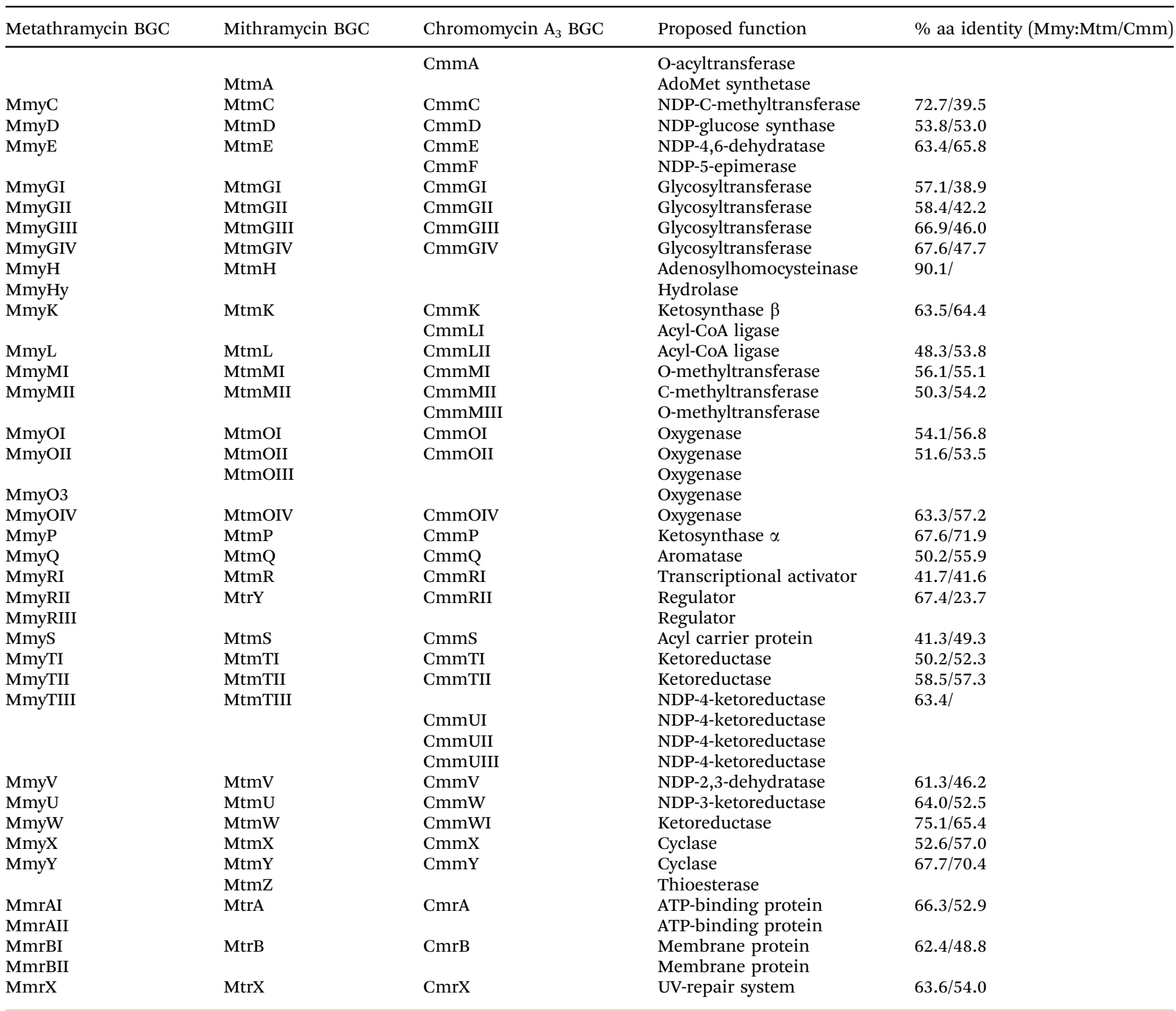

Table 2 Bioactivity assay results of antimicrobial and cytotoxicity assays

\begin{tabular}{llllll}
\hline & Premetathramycin (5) & Tetracycline & Nystatin & Mithramycin A (1) & Metathramycin (6) \\
\hline E. coli $\Delta$ tolC & $>128$ & 0.125 & ND & $>32$ & ND \\
B. subtilis E168 & 2 & 1 & ND & 0.004 & ND \\
S. cerevisiae $\Delta$ PDR & 32 & ND & 0.5 & 32 & ND \\
HCT-116 & 1.91 & ND & ND & 0.013 & 0.015
\end{tabular}

Antimicrobial minimum inhibitory concentration (MIC) assays were conducted for $\mathbf{5}$ with positive controls of tetracycline (antibacterial), nystatin (antifungal) and mithramycin A (Gram-positive antibacterial). Tumour cell cytotoxicity was performed with mithramycin A as a positive control

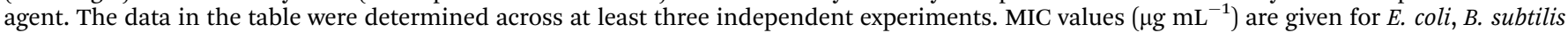
and $S$. cerevisiae. $\mathrm{IC}_{50}$ values $(\mu \mathrm{M})$ are given for HCT-116. ND, not determined.

Comparison of the annotated genes within the metathramycin BGC to those of mithramycin ${ }^{1,3}$ and chromomycin $\mathrm{A}_{3}{ }^{4}$ indicated that all of the genes necessary for biosynthesis of a tetracyclic aureolic acid aglycone premithramycinone (3) (mmyP, K, S, MI, OII, TI, TII) were present. Also present were genes for the subsequent methylation and glycosylation to a 
premithramycin B (4) analogue (mmyMII, GI-GIV) and the final ring opening and sidechain reduction characteristic of aureolic acid biosynthesis (mmyOIV, W). There were four glycosyltransferase genes present, indicating at least four sugars are likely to be present in the final product of the biosynthetic pathway. In previously described aureolic acids, the identity, configuration and connectivity of these sugars differed significantly. ${ }^{1,33-36}$ All known aureolic acids contain four to six sugars attached as two oligosaccharide chains composed of combinations of D-olivose, D-oliose D-mycarose and L-chromose B sugars. The metathramycin gene cluster lacked the required genes for chromomycin $\mathrm{A}_{3}$ style sugars - the epimerase $(\mathrm{CmmF})$ and subsequent reductase (CmmUIII) enzymes required for the production of L-chromose B, and methyl- and acyltransferase enzymes for further decoration (CmmMIII, A). The lack of a sugar epimerase gene indicates that all glycosylated metabolites of the metagenome pathway expression should only contain D-sugars. The metagenome cluster contained homologues indicative of a full sugar biosynthetic pathway for D-olivose, D-oliose and D-mycarose. The metagenome cluster contains a few notable genes that differ from either of the known aureolic acid biosynthesis pathways: The third oxygenase in the pathway (O3) does not have significant sequence homology to MtmOIII (chromomycin lacks a third oxygenase). The $\mathrm{O} 3$ gene has some homology to the DutO3 monoxygenase in dutomycin biosynthesis (51.6\% amino acid identity), as the nearest homologue in the MIBiG database. The metagenome gene cluster contains a HAD family hydrolase gene (Hy), which shares low-level identity with a putative hydrolase in streptolydigin biosynthesis $(56.4 \%$ amino acid identity). Also present is an extra regulatory protein (RIII) that aligns by BLASTp to TetR regulatory proteins.

\section{Heterologous expression of the biosynthetic gene cluster}

The complete BGC was delivered to $S$. albus $\mathrm{J} 1074$ by conjugation, and the resulting recombinant strain was cultivated in parallel with an empty vector control in $50 \mathrm{~mL}$ R5a medium containing $1 \mathrm{~g}$ Diaion HP-20 resin. Following 7 days of cultivation, the resin was collected, eluted with methanol and the resulting crude extracts were analysed by HPLC and LC-MS. Peaks potentially arising from aureolic acids were detected by monitoring absorbance at $420 \mathrm{~nm}$, and these were subsequently confirmed by examining a full absorbance spectrum and comparing this to the characteristic aureolic acid UV signature of a mithramycin standard. ${ }^{36,37}$ The primary findings of these experiments were that the major metabolite of this pathway had an $\mathrm{m} / \mathrm{z}$ of $975.3848[\mathrm{M}-\mathrm{H}]^{-}(\mathbf{5}$, corresponding to $\left.\mathrm{C}_{48} \mathrm{H}_{64} \mathrm{O}_{21}[\mathrm{M}-\mathrm{H}]^{-}=975.3867\right)$. However, the HPLC traces had many other smaller peaks with the same distinctive aureolic acid chromophore, some of which corresponded to aureolic acid pathway intermediates (Fig. 2B).

\section{Isolation and characterisation of premetathramycin}

To isolate and characterise the compounds arising from the metathramycin BGC, we scaled up production to a total of $7 \mathrm{~L}$ culture in R5a medium, and isolated $7.9 \mathrm{mg}$ of compound $\mathbf{5}$, the major metabolic product of the pathway. Compound $\mathbf{5}$ was a yellow film, and negative mode high-resolution electrospray ionization mass spectrometry [(-)-HRESIMS] analysis detected a deprotonated molecule at $\mathrm{m} / \mathrm{z} 975.3848$, consistent with the molecular formula $\mathrm{C}_{48} \mathrm{H}_{64} \mathrm{O}_{21}$ requiring 18 double bond equivalents. The UV/vis spectrum of $\mathbf{5}$ also corroborated the presence of a highly unsaturated and conjugated aromatic compound, with absorbance maxima at 228, 280, 330 and $415 \mathrm{~nm}$ consistent with aureolic acid type compounds, while the IR spectrum showed evidence of carbonyl stretches with peaks at 1628 and $1598 \mathrm{~cm}^{-1}$ (S12, ESI $\dagger$ ). This formula is isomeric with the previously reported aureolic acid compound chromocyclomycin $(7)^{36,38,39}$ which is structurally related to mithramycin, however, contains a fourth ring in the aglycone core rather than the tail at C-3 in 1. Compound 5 had a specific rotation of $[\alpha]_{\mathrm{D}}^{20}=-183$ ( $c=0.3$, ethanol) comparable to that reported for chromocyclomycin $\left([\alpha]_{\mathrm{D}}^{20}=-180(c=0.3\right.$, ethanol $\left.)\right)$.

Although compound 5 was soluble in several individual NMR solvents $\left(\mathrm{CDCl}_{3}, \mathrm{CD}_{3} \mathrm{OD}, \mathrm{DMSO}-\mathrm{d}_{6}\right)$, significant peak broadening was observed and many correlations in the $2 \mathrm{D}$ experiments were absent. A mixture of $1: 1 \mathrm{CDCl}_{3}: \mathrm{CD}_{3} \mathrm{OD}$ gave the sharpest signals, where the ${ }^{1} \mathrm{H}$ NMR spectrum showed two aromatic singlet methines at $\delta_{\mathrm{H}} 6.85$ and 6.71 and numerous other signals indicative of glycosylation, notably four anomeric doublet methines at $\delta_{\mathrm{H}} 5.57,5.37,4.91$ and 4.58 that suggested the metabolite had four sugars. The ${ }^{13} \mathrm{C}$ spectrum showed 48 signals, including three highly deshielded carbonyls $\left(\delta_{\mathrm{C}} 200.4,199.2\right.$ and 196.9), $11 \mathrm{sp}^{2}$ hybridised carbons $\left(\delta_{\mathrm{C}}\right.$ 164.9-101.2), one methoxy $\left(\delta_{\mathrm{C}}\right.$ 59.8) and eight methyl carbons, four of which $\left(\delta_{\mathrm{C}} 18.4,18.3,17.9\right.$ and 16.8) correlated (HSQC) with doublet ${ }^{1} \mathrm{H}$ resonances in the ${ }^{1} \mathrm{H}$ NMR spectrum while the others correlated to singlets $\left(\delta_{\mathrm{C}} 27.4,26.9,26.9\right.$ and 8.4).

The NMR and UV/vis spectral data was consistent with the aglycone portion of 5 being the same as that reported for chromocyclomycin, which was previously termed chromocyclin. ${ }^{39}$ This structure included the two aromatic singlet methines, of which $\delta_{\mathrm{H}} 6.71$ showed $\mathrm{HMBC}$ correlations to $\delta_{\mathrm{C}} 160.4,112.2$ and 108.5 (C-11, C-12 and C-14 respectively) and thus, alongside shared HMBC correlations to C-11 and C-12 with aromatic methyl $\delta_{\mathrm{H}}$ $2.13\left(\mathrm{H}_{3}-22\right)$, assigned it to $\mathrm{H}-10$. This proton also showed a ROESY correlation to the other aromatic methine $\delta_{\mathrm{H}} 6.85$, which placed them on the same side of the aromatic aglycone and was therefore assigned to $\mathrm{H}-8$, as it also showed a weak allylic COSY correlation to the spin system containing $\mathrm{H}_{2}-6, \mathrm{H}-5$ and $\mathrm{H}-4\left(\delta_{\mathrm{H}} 3.21 / 2.80,3.14\right.$ and 4.70 respectively). Shared HMBC correlations from $\mathrm{H}-5$ and $\mathrm{OCH}_{3}-21$ to $\mathrm{C}-4\left(\delta_{\mathrm{C}} 77.6\right)$ placed the methoxy group at C-4, while the acetyl group at C-2 $\left(\delta_{\mathrm{C}} 113.5\right)$ was evidenced by HMBC correlations from $\mathrm{H}_{3}-20\left(\delta_{\mathrm{H}} 2.49\right)$ to $\mathrm{C}-2$ and $\mathrm{C}-19\left(\delta_{\mathrm{C}} 200.4\right)$. There were no clear HMBC correlations to connect these two spin systems, however the ${ }^{13} \mathrm{C}$ chemical shifts are consistent with other chromocyclin containing congeners premithramycin $\mathrm{B}$ and prechromomycin $\mathrm{B} .{ }^{40}$ The MS/MS spectrum at low collision energy $(20.0 \mathrm{eV})$ further suggested this tetracyclic structure as opposed to the tricyclic, ring opened structure with a C-3 aliphatic sidechain that is present in many other aureolic acids. ${ }^{1}$ This aliphatic sidechain is the most readily fragmentable section of the metabolite and its loss is clearly observable in the MS/MS at low collision energies for both mithramycin (Fig. S1, ESI $\dagger$ ) and metathramycin (Fig. S3, ESI $\dagger$ ), however 
compound 5 shows no such fragmentation (Fig. S2, ESI $\dagger$ ). The relative configuration of C-4 and C-5 was determined through interpretation of the ROESY data. Mutual NOE correlations between $\mathrm{OCH}_{3}-21, \mathrm{H}-5$ and $\mathrm{H}-6 \mathrm{a}$ suggested they were on the same side of the molecule, corroborated by the relatively small coupling constant between $\mathrm{H}-5$ and $\mathrm{H}-6 \mathrm{a}(J=4.2 \mathrm{~Hz})$ which indicated a syn relationship. For $\mathrm{H}-6 \mathrm{~b}$, the large coupling constant to $\mathrm{H}-5$ $(J=11.0 \mathrm{~Hz})$ and lack of NOE correlations to $\mathrm{OCH}_{3}-21$ further supported this assignment. The relative configuration of $\mathrm{C}-18$ could not be determined from this spectroscopic evidence alone.

The carbohydrate moieties of compound 5 were assigned and characterised using a combination of COSY, HMBC, ROESY and HSQC-TOCSY NMR experiments. The anomeric resonance of sugar A, H-A1 $\left(\delta_{\mathrm{H}} 5.57\right.$, dd, $\left.J=2.2,9.6\right)$, showed an $\mathrm{HMBC}$ correlation to $\mathrm{C}-11\left(\delta_{\mathrm{C}} 160.4\right)$ thus connecting it to the aglycone core directly, while scalar ${ }^{1} \mathrm{H}-{ }^{1} \mathrm{H}$ coupling constants and ROESY correlations supported a mycarose sugar configuration (Fig. 3). The original reported structure of chromocyclomycin also contained a C-11 mycarose glycoside, present in an $\alpha$-configuration based on calculations of molecular rotations using Klyne's rule. ${ }^{36}$ The $\mathrm{H}-A 1{ }^{1} \mathrm{H}$ NMR resonance of compound $\mathbf{5}$ showed a large scalar coupling constant $\left(J_{A 1, A 2}=9.6 \mathrm{~Hz}\right)$ consistent with an axial-axial relationship to $\mathrm{H}_{2}-A 2 \mathrm{a}\left(\delta_{\mathrm{H}} 1.57\right)$, which suggested the glycoside is $\beta$-linked in contrast to that previously reported.

The NMR data of the remaining three carbohydrates bound at C-18 was consistent with an olivose-oliose-mycarose chain, the same as that reported for chromocyclomycin. The mycarose residue was again terminal, and its anomeric centre $\mathrm{H}-\mathrm{D} 1$ $\left(\delta_{\mathrm{H}} 4.91\right.$, dd $\left.J=2.1,9.7\right)$ showed an HMBC correlation to oliose C-C3 $\left(\delta_{\mathrm{C}} 76.8\right)$ while the major scalar coupling constant $\left(J_{D 1, D 2}=\right.$ $9.7 \mathrm{~Hz}$ ) again suggested a $\beta$-configuration. The oliose anomeric centre $\mathrm{H}-\mathrm{C} 1\left(\delta_{\mathrm{H}} 4.58\right)$ resonance was obscured by the water peak, however the large splitting of $\mathrm{H}-C 2 \mathrm{a}\left(\delta_{\mathrm{H}} 1.80, \mathrm{q}, J=12.2\right)$ is consistent with an axial-axial relationship and a $\beta$-configuration. Its connection to the olivose residue was determined by the $\mathrm{HMBC}$ correlation from $\mathrm{H}-\mathrm{C} 1$ to $\mathrm{C}-\mathrm{B} 3\left(\delta_{\mathrm{C}} 81.0\right)$. Although the ${ }^{13} \mathrm{C}$ resonance for $\mathrm{C}-18$ was not observed directly, the olivose residue is connected to the aglycone directly based on

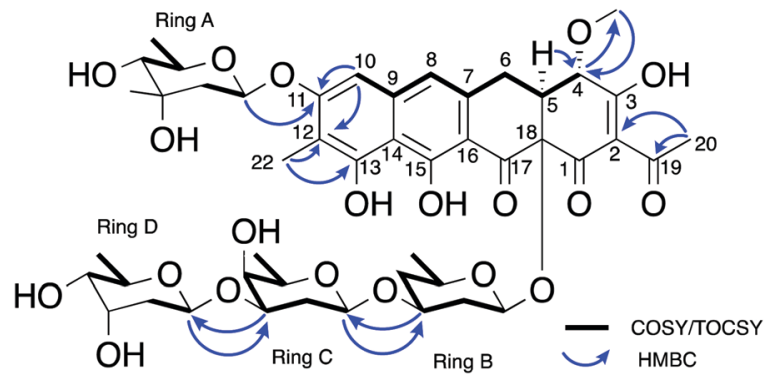

Fig. 3 Key NMR correlations used in elucidation of the structure of premetathramcyin: Key HMBC and COSY correlations in the NMR spectra of $\mathbf{5}$ consistent with the aglycone core of the proposed structure of chromocyclomycin $^{36,39}$ as well as Key HMBC and COSY/TOCSY correlations in the NMR spectra of premetathramcyin providing the glycosidic linkages are shown. biosynthetic considerations and is again $\beta$-configured based on the large coupling constant to $\mathrm{H}_{2}-B 2 \mathrm{a}\left(\delta_{\mathrm{H}} 1.62, \mathrm{q}, 11.7 \mathrm{~Hz}\right)$. The original reports of chromocyclomycin suggested a $\beta$-configuration for both olivose and oliose, and an $\alpha$-configuration for mycarose, thus varying from that determined for compound 5.

Compound 5 was not found to possess any Gram-negative antibiotic activity when assayed against $E$. coli, consistent with previously characterised aureolic acids. As the test strain lacks the central efflux pump TolC, it is likely that this intrinsic resistance is not mediated by efflux. Compound $\mathbf{5}$ did possess moderate/strong Gram-positive antibiotic activity (B. subtilis E168, MIC $2 \mu \mathrm{g} \mathrm{mL}{ }^{-1}$ ), however a mithramycin A standard had an MIC of $0.004 \mu \mathrm{g} \mathrm{mL} \mathrm{m}^{-1}$, indicating 500-fold greater Grampositive antibacterial potency relative to $\mathbf{5}$. Compound 5 also possessed moderate cytotoxic activity against the HCT-116 cancer cell line, with an $\mathrm{IC}_{50}$ of $1.91 \mu \mathrm{M}$. However, mithramycin A was again far more potent, with an $\mathrm{IC}_{50}$ of $0.017 \mu \mathrm{M}$.

Chromocyclomycin has only been described in three research publications, where the biological activity is either not defined $^{36,41}$ or it is stated to be "biologically inactive". 38 Another analogous compound, the tetracyclic aureolic acid precursor premithramycin $\mathrm{B}$, has also been demonstrated to possess no detectable antibiotic activity (no inhibition of Micrococcus luteus growth up to $50 \mu \mathrm{g}$ in an agar spot bioassay). ${ }^{40}$ However, 5 has here been demonstrated to possess Grampositive antibiotic activity comparable to that of tetracycline. Likewise, 5 possessed moderate cytotoxicity in the HCT-116 cell line. These results indicate that 5 possesses not only a novel chemical structure, but also a novel bioactivity profile.

\section{Bioactivity guided fractionation and discovery of metathramycin}

The potent bioactivities of aureolic acid family compounds are exclusively found in those with a tricyclic core and aliphatic tail motif $(\mathbf{1}, 2)$, which are generated from tetracyclic precursors by characterised ring opening pathway of two enzymes MtmOIV,W/CmmOIV,W. ${ }^{40,42,43}$ The metathramycin BGC contains gene homologues for these enzymes, leading us to speculate that we might have been missing the final product of the pathway. As known mature aureolic acid compounds are highly active Gram-positive antibiotics, we conducted bioactivity-guided fractionation of our fermentation extract to find this putative missing metabolite.

A sample of the crude fermentation extract was fractionated over an HPLC gradient, with fractions testing positive by agar zone of inhibition assays to the Bacillus subtilis 168 test strain being pooled and re-fractionated at a shallower gradient. Three rounds of this process culminated in a sample containing an ion with $m / z 967.4186[\mathrm{M}-\mathrm{H}]^{-}$that possessed potent bioactivity (6, corresponding to $\mathrm{C}_{47} \mathrm{H}_{68} \mathrm{O}_{21}$ calcd 967.4180, $\Delta=0.6 \mathrm{ppm}$ ). Notably, the mass difference between 5 and 6 (976.3928$968.4256=7.9672 \mathrm{Da})$ is the same mass difference between premithramycin B and mithramycin (1092.4414-1084.4727 = 7.9687 Da), indicating a similar biochemical transformation. 
The production of 6 in $S$. albus::MMY culture was extremely low, and the amount isolated from $7 \mathrm{~L}$ of culture was insufficient to allow use of standard quantification methods. The purified sample was instead quantified by comparison to an injection standard of mithramycin by HPLC and measurements of UV absorption. As mithramycin and the predicted structure of 6 carry identical chromophores, the absorbance of the mithramycin standard was used to quantify the sample of 6 . After normalisation for the mass difference and assuming the extinction coefficient difference is negligible, the calculated quantity of compound 6 was $7.2 \mu \mathrm{g}$.

This low yield $\left(\sim 1 \mu \mathrm{g} \mathrm{L}^{-1}\right)$ precluded structure elucidation by NMR, however MS/MS fragmentation analysis was conducted of $\mathbf{6}$ and the major biosynthesis product compound $\mathbf{1}$ against an authentic sample of mithramycin (Fig. 4). Compound 6 fragmented similarly to the mithramycin standard, with some of the fragmented ions shifted by a mass corresponding to the loss of a deoxy sugar and the gain of a methyl group, consistent with the mass difference between mithramycin and 6. The observed fragmentation pattern in both cases initiated with the loss of the aliphatic sidechain (daughter ion $\mathrm{m} / z 820$ or 935 ) at $20.0 \mathrm{eV}$, then successive loss of deoxy sugars up to $60.0 \mathrm{eV}$, leaving the tricyclic core at $\mathrm{m} / \mathrm{z} 269$. The observed mass and fragmentation patterns of $\mathbf{6}$ are consistent with a "ring opened" aureolic acid. This fragmentation pathway was consistent with the gene cluster analysis, where the presence of OIV and $\mathrm{W}$ homologues indicate a ring opening step should occur in the biosynthesis pathway as for mithramycin and chromomycin $\mathrm{A}_{3}$. Compound 5 did not follow the same fragmentation pattern as the mithramycin standard (Fig. S2, ESI $\dagger$ ), potentially due to the lack of an aliphatic tail where the initial fragmentation occurs (at $20.0 \mathrm{eV}$ onwards). Instead, the parent ion of 5 remained intact at $20.0 \mathrm{eV}$, with only minor fragmentation at $40.0 \mathrm{eV}$, followed by seemingly disordered breakdown at $60.0 \mathrm{eV}$, from which three of the conserved core masses observed during fragmentation of both mithramycin and compound 6 could be identified (Fig. S2, ESI $\dagger$ ).

The metathramycin BGC contained homologues of both $m t m O I V$ and $m t m W$. These are believed to encode enzymes that catalyse oxidative cleavage of the fourth ring in the tetracyclic core of premithramycin, and reduction of the resulting sidechain, respectively, to yield mithramycin (Fig. 5A). ${ }^{40,43}$ To further test the hypothesis that compound $\mathbf{6}$ was indeed the product of enzymatic opening of the fourth ring of 5, we

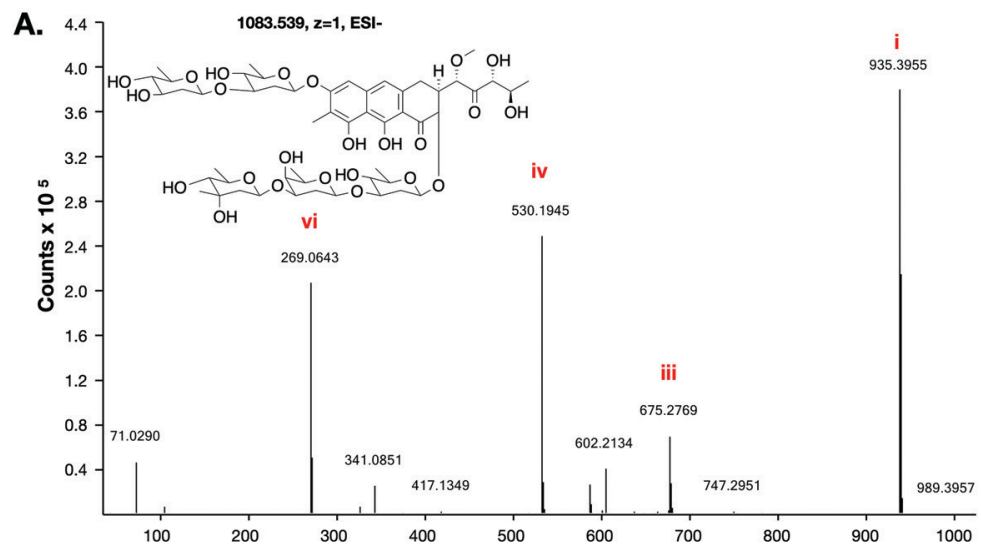

C.
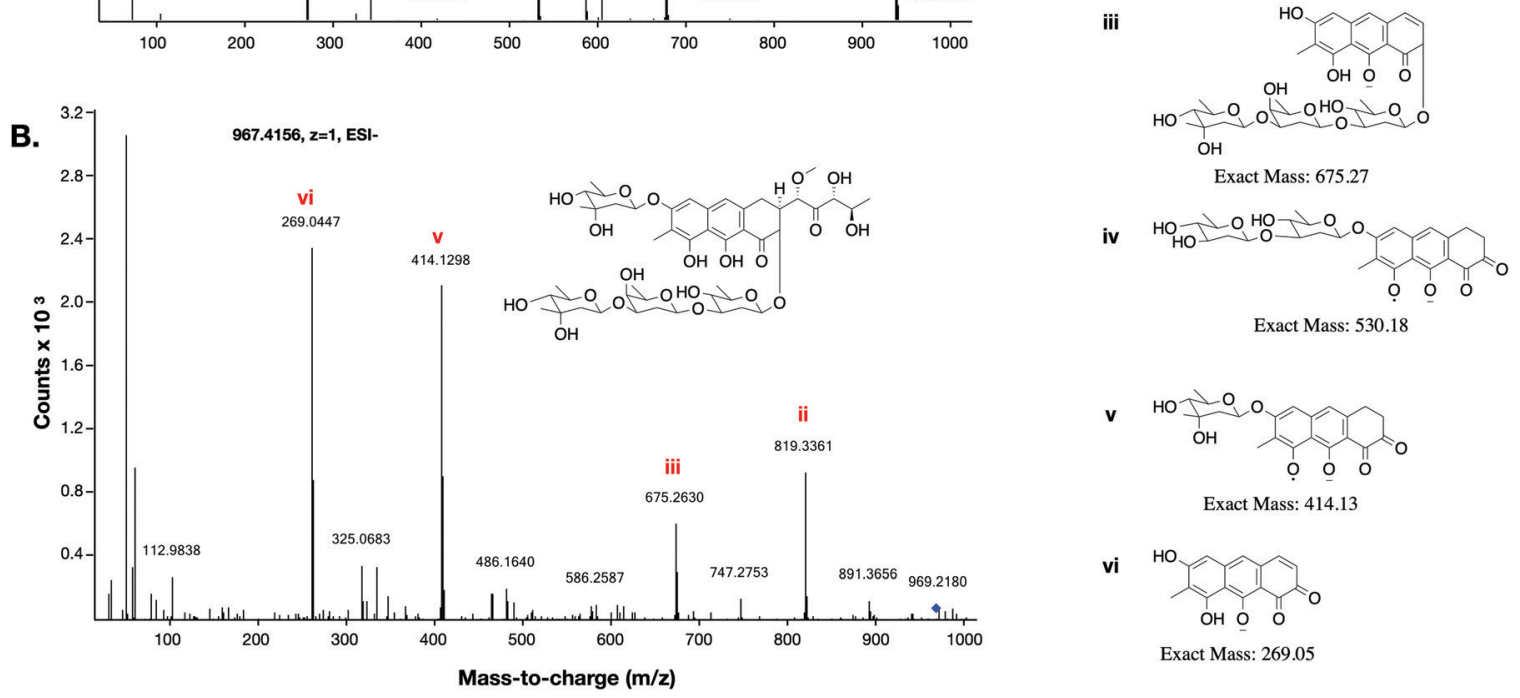

Exact Mass: 530.18

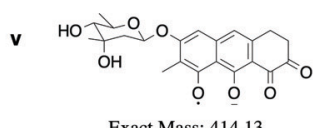

vi

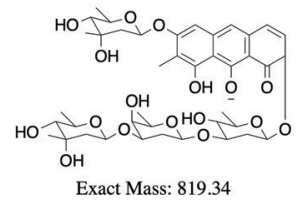

i

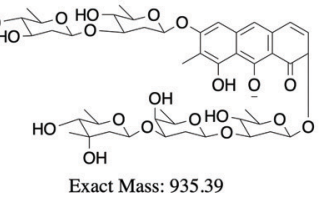

i

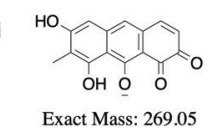

Fig. 4 MS/MS fragmentation of mithramycin and metathramycin: MS/MS spectra obtained with a collision energy of $60.0 \mathrm{eV}$ are depicted. (A) Tandem MS showing a possible fragmentation pattern from a sample of mithramycin. Two of the observed daughter ions also occur in panel B. (B) Tandem MS fragmentation pattern of metathramycin. The non-conserved fragment ions $\mathrm{m} / \mathrm{z}$ differ from those of mithramycin by 116 (i.e. $935-819$ and $530-414$ ), equivalent to the mass difference between mithramycin and metathramycin. (C) Putative structures for observed fragment ions. 
amplified the mmyOIV and mmyW genes from our pathway and cloned these into the integrative vector pIJ10257 as a bi-cistronic unit under control of the constitutive promoter $e^{*} E^{*}$. The PCR primers were designed to include a unique Shine-Dalgarno sequence ${ }^{44}$ as a point of homology between the two genes to complete the assembly and allow for expression from a single promoter sequence. The resulting construct was integrated into the $S$. albus strain harbouring the complete biosynthetic pathway, and production of $\mathbf{6}$ quantitated using LC-MS. We found that over-expression of the putative ring opening enzymes resulted in a 1.9-fold increase in 6 production compared to the base expression strain (Fig. 5B), providing further evidence to support the hypothesis that compound $\mathbf{5}$ is not the (sole) final product of the biosynthesis pathway, and that compound 5 may be converted to compound 6 by the same mechanism as conversion of premithramycin $\mathrm{B}$ to mithramycin. Given that $\mathbf{6}$ appears to be a direct conversion product afforded by ring opening and side chain reduction of 5 , it is reasonable to assume that the configuration and connectivity of sugars is conserved between these two compounds.

Pleasingly, the $7.2 \mu \mathrm{g}$ that was isolated was sufficient to conduct a bioactivity assay. When tested against the human tumour cell line HCT-116, metathramycin demonstrated potent cytotoxicity comparable to that of mithramycin (Fig. 5C: mithramycin $1 \mathrm{IC}_{50}=13.4 \mathrm{nM}$, metathramycin $6 \mathrm{IC}_{50}=14.6 \mathrm{nM}$ over 4 biological replicates). Although there was insufficient compound to perform initial toxicology studies, the promising bioactivity of metathramycin against tumour cells suggests that further analysis of this molecule is warranted.

\section{Concluding remarks}

While the task of generating bioactive mithralogs in the laboratory continues, it is apparent that there are aureolic acids in nature yet to be discovered. Metagenome mining studies in recent years have uncovered polyketide biosynthetic pathways that phylogenetically map to aureolic acid biosynthesis. ${ }^{10}$ This study is the first to characterise the aureolic acid chemical output of a metagenome-derived BGC.

Heterologous expression of this biosynthetic gene cluster resulted in a major fermentation product (5) that was not the final product of the biosynthetic pathway (6). The molecular formula of the major metabolite (5) was determined by HR-MS to be $\mathrm{C}_{48} \mathrm{H}_{64} \mathrm{O}_{21}$, which is identical to a known aureolic acid, chromocyclomycin. Subsequent isolation of $\mathbf{5}$ revealed that it was not chromocyclomycin, but instead a derivative structure where the glycosidic linkages were exclusively in the $\beta$ configuration; in contrast, the two mycarose sugars in chromocyclomycin are $\alpha$-linked. While literature evidence on the bioactivity of chromocyclomycin is limited, our data demonstrated here indicate the different configurations of the mycarose sugars have resulted in a different bioactivity profile between the two compounds.

Uncovering the mature product of the metathramycin gene cluster required us to integrate bioinformatic analysis, pathway engineering, and knowledge from previous biochemical and heterologous expression studies of aureolic acid BGCs. The structure of the major metabolite arising from heterologous expression was not consistent with the gene content of the BGC, suggesting this was not the final product. Bioactivity guided fractionation allowed us to isolate an extremely minor constituent 6 from a complex mixture of biosynthetic intermediates and shunt products, and analysis of fragmentation data from MS/MS experiments allowed a planar structure to be predicted. Finally, overexpression of key genes in the pathway supported our assertion that this was the product of a defined biosynthetic conversion from a metabolite for which we had attained detailed structural data, allowing us to propose likely stereochemistry for the final product of the pathway. Metathramycin was also demonstrated to have potent cytotoxic activity in HCT-116 cells, in keeping with the strong anticancer activities of previously reported aureolic acids. Such a discovery approach may
A.

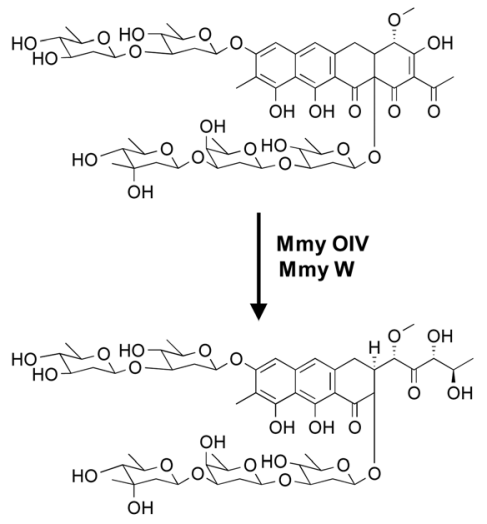

B.

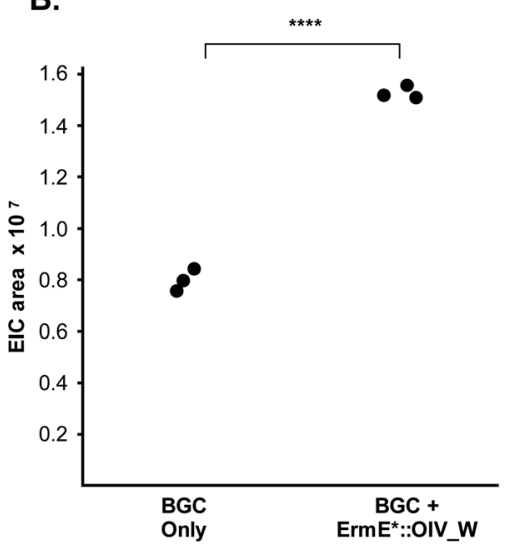

C.
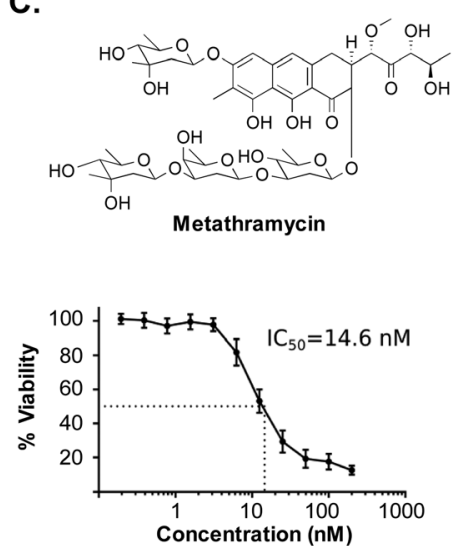

Fig. 5 Pathway engineering provides evidence that metathramycin is the product of direct biosynthetic conversion from premetathramycin: (A) reaction catalysed by OIV, W enzymes in the biosynthesis of mithramycin. (B) Overexpression of the OIV, W homologues under the control of a strong constitutive promoter results a 1.9 fold increase in production of metathramycin as compared to a strain containing these genes under the control of a native promoter, data for three biological replicates are shown. (C) MTS assay against the human tumour cell line HCT-116 ( $n=4)$ shows metathramycin possesses potent cytotoxicity comparable to that of mithramycin. 
be generalisable to other families of natural product where biosynthetic gene clusters describe well characterised biosynthetic transformations, as has been previously applied for elucidation of stereochemistry. ${ }^{45}$ Without the prior in depth characterisation of aureolic acid biosynthesis by other research groups, ${ }^{40,42,43}$ such an approach would not have been possible, and it is unlikely that the final product of this pathway would have been discovered.

Future studies may now take place with the metathramycin gene cluster as a basis for combinatorial biosynthesis or derivatisation, as has been performed previously in the search for mithralogs. ${ }^{6}$ Other manipulations of biosynthetic pathway regulation may permit greater compound production of 6 to permit further analysis with different cell lines or biological targets. ${ }^{3,26,28}$ The approach used in this study may be applied to future discovery pipelines to find new mithralogs or other low abundance bioactive metabolites.

\section{Methods}

\section{Construction of soil metagenome cosmid library}

A soil sample of $\sim 1 \mathrm{~kg}$ was collected from Half Moon Bay, Kaikōura New Zealand. A sample of $250 \mathrm{~g}$ was weighed into a $1 \mathrm{~L}$ centrifuge bottle, with $270 \mathrm{~mL}$ heated $\left(70{ }^{\circ} \mathrm{C}\right)$ lysis buffer (100 mM Tris-HCl, $100 \mathrm{mM}$ Na EDTA, $1.5 \mathrm{M} \mathrm{NaCl,} \mathrm{1 \%} \mathrm{(w/v)}$ cetyl trimethyl ammonium bromide, pH 8.0) added. This was mixed to ensure the soil was thoroughly wetted, and returned to the water bath to reach $70{ }^{\circ} \mathrm{C}$. A volume of $30 \mathrm{~mL}$ heated $\left(70{ }^{\circ} \mathrm{C}\right)$ $20 \% \operatorname{SDS}(\mathrm{w} / \mathrm{v})$ was added to the centrifuge tube, inverted to mix, and returned to the water bath. The sample was incubated for $2 \mathrm{~h}$, with gentle inversion every $30 \mathrm{~min}$. The sample was then rapidly cooled in an ice/water bucket for $30 \mathrm{~min}$, with inversion once in this time. The soil and chilled precipitate were then separated from the clarified lysate by centrifugation at $4500 \mathrm{rcf}$ for $35 \mathrm{~min}$ at $4{ }^{\circ} \mathrm{C}$. The supernatant was recovered, volume measured, and returned to room temperature by brief incubation in the warm water bath. Isopropanol was added to $0.7 \times$ the supernatant volume, and mixed by gentle inversion to precipitate the eDNA. Following a $30 \mathrm{~min}$ room temperature incubation, the precipitated eDNA was collected by centrifugation at $4500 \mathrm{rcf}$ for $35 \mathrm{~min}$ at $4{ }^{\circ} \mathrm{C}$. The supernatant was discarded, and the eDNA pellet and centrifuge bottle was washed with $100 \mathrm{~mL}$ of ice cold $70 \%(\mathrm{v} / \mathrm{v})$ ethanol. The sample was again centrifuged at $4500 \mathrm{rcf}$ for $10 \mathrm{~min}$ at $4{ }^{\circ} \mathrm{C}$. The supernatant was discarded, and the bottle briefly centrifuged again to collect the remaining ethanol, which was removed by pipette. The eDNA pellet was briefly air dried (no more than $15 \mathrm{~min}$ ). A minimum volume of TE buffer was added to cover the eDNA pellet, and this was left to slowly resuspend overnight at room temperature.

The eDNA substrate for cosmid library construction was then size selected by agarose gel extraction in $0.8 \%$ agarose $1 \times$ TAE gel run at $80 \mathrm{~V}$ for $2 \mathrm{~h}$ alongside $\lambda$ HindIII marker, then overnight in fresh TAE at $18 \mathrm{~V}$. DNA above the $23 \mathrm{~kb}$ marker was excised from the gel and electroeluted, then concentrated using a $30000 \mathrm{kDa}$ molecular weight cut-off column centrifugal concentrator. The DNA sample was quantified by nanodrop, then end-repaired using End-It DNA End-Repair Kit (Epicentre).

The cosmid vector pWEB::tnc was prepared by digested with SmaI restriction enzyme (NEB), and dephosphorylation with Antarctic phosphatase (NEB) according to the manufacturer's instructions. The prepared cosmid vector (250 ng) and eDNA substrate $(125 \mathrm{ng})$ were then ligated in a final reaction volume of $5 \mu \mathrm{L}$ using Fast-link DNA ligase (Epicentre) according to the manufacturer's instructions. Phage packaging extract was prepared in house according to Winn and Norris (2010), and used to package the ligated DNA. The resulting diluted phage heads were added in a 1:10 ratio to an ice cold, day culture of E. coli EC100 (or EC100 $\Delta e n t D$ ) grown to $\mathrm{OD}_{600}$ of 1.0 in $\mathrm{LB}$ $10 \mathrm{mM} \mathrm{MgSO}$. The phage head/cell mixture was incubated at room temperature for $20 \mathrm{~min}$, then aliquoted across 96 wells and incubated at $37{ }^{\circ} \mathrm{C} 200 \mathrm{rpm}$ for $75 \mathrm{~min}$. The recovered, transfected $E$. coli cells were then diluted in LB Amp Chl for cosmid selection, and titre samples of select wells plates plated on LB Amp Chl agar, for colony counting and library size estimations. The remaining cultures were incubated overnight at $37{ }^{\circ} \mathrm{C} 200 \mathrm{rpm}$ to replicate the library clones in liquid culture. The following morning, samples were taken from each of the 96 aliquots to make glycerol stocks for long term storage, alongside minipreps of each library "well".

\section{Sequencing of clones, bioinformatic interrogation}

Cosmids and BACs to be sequenced were isolated from E. coli cultures by miniprep, and Macrogen Inc. performed both Sanger and Illumina HiSeq PE100 bp sequencing. Sanger sequencing primers for cosmid end sequencing were standard T7pro and M13F-pUC primers.

Illumina HiSeq (100 bp PE) reads were pre-processed to remove pWEB::tnc vector sequence and contaminating $E$. coli gDNA sequences using bowtie $2,{ }^{46}$ followed by read quality trimming and sequencing adapter removal by Trimmomatic. ${ }^{47}$ The resulting processed Illumina PE reads were then assembled using SPAdes genome assembler. ${ }^{24}$

\section{Transformation associated recombination}

The E. coli:yeast:Streptomyces shuttle vector, pTARa, was retrofit with a synthetic DNA block via Gibson assembly to produce the TAR capture vector. The synthetic DNA contains 712 bp homology capture arms to each of the cosmid insert sequences, separated by a PmeI restriction site. To prepare for TAR, the vector was linearised by PmeI digestion. Cosmid inserts were liberated from the pWEB::tnc vector by in vitro Cas9 digestion. The CRISPR guide RNAs target to the pWEB::tnc vector $\sim 190 \mathrm{nt}$ upstream of the cosmid insert site (GGTTATTGTCTCATGAG), and $\sim 115 \mathrm{nt}$ downstream of the cosmid insertion site (GTTAAATTGCTAACGCAGTC).

The three linear DNA units were transformed into $S$. cerevisiae BY4727 $\Delta D \ln 4^{32}$ for recombination and reconstitution of the BGC with the BAC. The Kallifidias and Brady (2012) protocol was followed for the preparation of yeast spheroplasts, and for the transformation of the spheroplasts with pTARa capture vector and overlapping clones. 


\section{Conjugation into Streptomyces albus expression host}

Constructs to be conjugated into Streptomyces were first transformed by electroporation into E. coli S17-1. Overnight cultures of the S17-1 "donor" strain were sub inoculated into fresh LB with appropriate antibiotics, and cultured at $37{ }^{\circ} \mathrm{C}$ until $\mathrm{OD}_{600}$ reached 0.5-1.0. S17-1 cultures were then chilled and washed in fresh ice-cold LB broth, and resuspended in a final volume of $1 \mathrm{~mL}$ LB. The "recipient" $S$. albus J1074 spore stock was diluted into $0.5 \mathrm{~mL}$ TSB or $\mathrm{LB}$, and heat shocked at $50{ }^{\circ} \mathrm{C}$ for $10 \mathrm{~min}$.

The donor and recipient stocks were then mixed in a $1: 1 \mathrm{v} / \mathrm{v}$ ratio, and centrifuged at $4000 \mathrm{rcf}$ for $5 \mathrm{~min}$. The cell pellet was resuspended in 50-100 $\mu \mathrm{L}$ of the residual $\mathrm{LB}$, and spread onto ISP4 agar, without antibiotics. Plates were incubated for $12-16 \mathrm{~h}$ at $30^{\circ} \mathrm{C}$, and then flooded with $1 \mathrm{~mL}$ of the appropriate antibiotic stock mix (for pTARa $0.5 \mathrm{mg} \mathrm{mL} \mathrm{m}^{-1}$ nalidixic acid, $1.25 \mathrm{mg} \mathrm{mL}^{-1}$ apramycin sulfate, and for pIJ10257 $0.5 \mathrm{mg} \mathrm{mL}^{-1}$ nalidixic acid, $2.0 \mathrm{mg} \mathrm{mL}^{-1}$ hygromycin). Plates were incubated at $30{ }^{\circ} \mathrm{C}$ for $24-72 \mathrm{~h}$ until colonies emerged.

\section{Spectroscopic analysis}

Optical rotations were measured using a Rudolph Autopol II polarimeter. A JEOL JNM-ECZ600R with a nitrogen cooled $5 \mathrm{~mm}$ SuperCOOL cryogenic probe was used to record the NMR spectra of all compounds $\left(600 \mathrm{MHz}\right.$ for ${ }^{1} \mathrm{H}$ nuclei and $150 \mathrm{MHz}$ for ${ }^{13} \mathrm{C}$ nuclei). The residual solvent peak was used as an internal reference for ${ }^{1} \mathrm{H}\left(\delta_{\mathrm{H}} 3.31, \mathrm{CD}_{3} \mathrm{OD} ; 7.26, \mathrm{CDCl}_{3}\right)$ and ${ }^{13} \mathrm{C}\left(\delta_{\mathrm{C}} 49.0, \mathrm{CD}_{3} \mathrm{OD} ; 71.6, \mathrm{CDCl}_{3}\right)$ chemical shifts. ${ }^{48}$ Standard pulse sequences supplied by JEOL were used for NMR analyses. High-resolution (ESI) mass spectrometric data was obtained with an Agilent 6530 Accurate Mass Q-TOF LCMS equipped with a 1260 Infinity binary pump. IR (film) spectra were recorded using a Bruker Platinum Alpha FTIR spectrometer, while UV/vis spectra were extracted from HPLC chromatograms.

Reversed-phase column chromatography was achieved using Supelco Diaion HP20 (PSDVB) chromatographic resin. Size exclusion chromatography was achieved using Sephadex LH20 resin. HPLC purifications were carried out using a Rainin Dynamax SD200 solvent delivery system with $25 \mathrm{~mL}$ pump heads with a Varian Prostar 335 diode array detector. Octadecyl-derivatised silica $\left(\mathrm{C}_{18}\right.$, $5 \mu \mathrm{m}, 100 \AA$ A) HPLC columns (Phenomenex) were either analytical

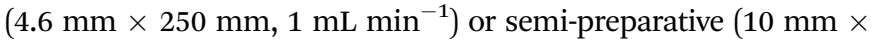
$\left.250 \mathrm{~mm}, 4 \mathrm{~mL} \min ^{-1}\right)$, while a Phenomenex Luna octylderivatised silica gel $\left(\mathrm{C}_{8}\right)$ column (analytical; $4.6 \mathrm{~mm} \times$ $250 \mathrm{~mm}, 1 \mathrm{~mL} \min ^{-1}$ ) was also used. All solvents used were of HPLC grade and $\mathrm{H}_{2} \mathrm{O}$ was glass distilled. Solvent mixtures are reported as percent volume/volume.

\section{Production and isolation of premetathramycin and metathramycin}

Cultures of $S$. albus J1074::MMY were grown in 7 L total R5a medium, with $1 \%$ inoculum from a mature seed culture grown in TSB medium. R5a cultures were prepared with the addition of $20 \mathrm{~g} \mathrm{~L}^{-1}$ of HP20 resin to collect metabolites as they were produced during the 7-day culture time. The HP20 was washed with $1 \mathrm{~L}$ of $\mathrm{H}_{2} \mathrm{O}$, and $1500 \mathrm{~mL}$ of $20 \%$ methanol/ $\mathrm{H}_{2} \mathrm{O}$, before elution in $1500 \mathrm{~mL} 80 \%$ methanol $/ \mathrm{H}_{2} \mathrm{O}$. The $1500 \mathrm{~mL}$ elution was dried under reduced pressure, resuspended in $80 \mathrm{~mL}$ of methanol, and undissolved particulate removed via centrifugation. The clarified supernatant was dried, with a mass of 1091 mg. Half of this sample was then resuspended in methanol, syringe filtered, and partitioned on an LH20 column run in methanol, with $5 \mathrm{~mL}$ fractions collected and combined based on MS analysis for the presence of the protonated molecular ion of 5. Four early fractions were combined, and were dried under reduced pressure to a dry mass of $262 \mathrm{mg}$. This sample was purified by semi-preparative $\mathrm{C}_{18}$ HPLC with a gradient of 10$100 \%$ methanol $/ \mathrm{H}_{2} \mathrm{O}(0.2 \%$ formic acid $)$ over $60 \mathrm{~min}$. Two fractions were collected, one containing the ion for compound $6(8.0 \mathrm{mg})$ with a retention time of $51.5 \mathrm{~min}$ and another with compound $5(19.7 \mathrm{mg})$ that had a retention time of $52.3 \mathrm{~min}$. The first sample was purified by analytical $\mathrm{C}_{18}$ HPLC using an isocratic method of $70 \%$ methanol $/ \mathrm{H}_{2} \mathrm{O}$ ( $0.2 \%$ formic acid), to give compound $6(7.2 \mu \mathrm{g})$. A $10 \mathrm{mg}$ portion of the second sample was also purified by analytical $\mathrm{C}_{18} \mathrm{HPLC}\left(75 \%\right.$ methanol $/ \mathrm{H}_{2} \mathrm{O}$ $(0.2 \%$ formic acid)), to give compound $5(7.9 \mathrm{mg})$. This represents a recovery of $4.4 \mathrm{mg} \mathrm{L}^{-1}$ of culture (when accounting for the unprocessed sample at each stage of purification).

Premetathramycin (5): yellow solid; $[\alpha]_{\mathrm{D}}^{20}-183$ (c 0.3, EtOH); $\mathrm{UV}(\mathrm{MeOH}) \lambda_{\max } 228,280,330,415 \mathrm{~nm}$; IR (film) $v_{\max } 3382$, 2928, 1628, 1598, 1530, 1370, $1065 \mathrm{~cm}^{-1} ;{ }^{1} \mathrm{H}$ NMR (1: $1 \mathrm{CD}_{3} \mathrm{OD}$ : $\mathrm{CDCl}_{3}$ ) Tables S1 and S2 ESI; $\dagger{ }^{13} \mathrm{C}$ NMR (1:1 $\left.\mathrm{CD}_{3} \mathrm{OD}: \mathrm{CDCl}_{3}\right)$ Tables S1 and S2 ESI; $\dagger(-) H R E S I M S ~ m / z ~ 975.3848[\mathrm{M}-\mathrm{H}]^{-}$ (calcd for $\mathrm{C}_{48} \mathrm{H}_{64} \mathrm{O}_{21}, 975.3867, \Delta=-1.9 \mathrm{ppm}$ ).

\section{Antimicrobial testing}

Minimum inhibitory concentration (MIC) studies were performed using an established protocol ${ }^{49}$ to test isolated compounds against test strains of E. coli $\Delta$ tolC $(7 \mathrm{NT})^{50}$ and B. subtilis 168. All tests were carried out in $\mathrm{MH}$ medium at $30{ }^{\circ} \mathrm{C}$, with $16 \mathrm{~h}$ growth time in biological triplicates $(n=3$ independent experiments). Positive controls of tetracycline and mithramycin A were included in the analysis. All compounds were assayed from $128 \mu \mathrm{g} \mathrm{mL}^{-1}$ in two-fold serial dilution steps across 20 dilution stages, except for mithramycin, where the starting concentration was $32 \mu \mathrm{g} \mathrm{mL}{ }^{-1}$. Sterility (media only) and growth (cells only) controls were included in each plate assayed.

The same protocol was followed for fungal MICs against $S$. cerevisiae lacking the pleiotropic drug resistance gene PDR4, with the growth medium YPD, and the positive control antibiotic nystatin. The end-point measurement was changed from an eyesight measure to optical density, where a growth inhibited well was one where the OD measurement was $<90 \%$ of the growth control well (as per EUCAST guidelines for fungal susceptibility testing).

\section{Tumour cell cytotoxicity assay}

A standard $48 \mathrm{~h}$ MTS cell proliferation assay was used to evaluate cytotoxic activity against the human colon carcinoma cell line HCT-116 ( $n=4$ independent experiments). Cells were treated with compound at various concentrations, and a dose-response was generated relative to a control of untreated 
HCT-116 cells. A positive control of mithramycin A was used in all cases.

\section{Conflicts of interest}

There are no conflicts to declare.

\section{References}

1 F. Lombó, N. Menéndez, J. A. Salas and C. Méndez, Appl. Microbiol. Biotechnol., 2006, 73, 1-14.

2 L. L. Remsing, A. M. González, M. Nur-e-Alam, M. J. FernándezLozano, A. F. Braña, U. Rix, M. A. Oliveira, C. Méndez, J. A. Salas and J. Rohr, J. Am. Chem. Soc., 2003, 125, 5745-5753.

3 F. Lombó, A. F. Braña, C. Méndez and J. A. Salas, J. Bacteriol., 1999, 181, 642-647.

4 N. Menéndez, M. Nur-e-Alam, A. F. Braña, J. Rohr, J. A. Salas and C. Méndez, Chem. Biol., 2004, 11, 21-32.

5 J. G. Sabín, Biochem. Pharmacol. Open Access, 2013, 2, 1-3.

6 C. Méndez, J. González-Sabín, F. Morís and J. A. Salas, Planta Med., 2015, 81, 1326-1338.

7 I. Baig, M. Perez, A. F. Braña, R. Gomathinayagam, C. Damodaran, J. A. Salas, C. Méndez and J. Rohr, J. Nat. Prod., 2008, 71, 199-207.

8 L. E. Núñez, S. E. Nybo, J. González-Sabín, M. Pérez, N. Menéndez, A. F. Braña, K. A. Shaaban, M. He, F. Morís, J. A. Salas, J. Rohr and C. Méndez, J. Med. Chem., 2012, 55, 5813-5825.

9 D. J. Newman and G. M. Cragg, J. Nat. Prod., 2016, 79, 629-661.

10 Z. Feng, D. Kallifidas and S. F. Brady, Proc. Natl. Acad. Sci. U. S. A., 2011, 108, 12629-12634.

11 H. S. Kang and S. F. Brady, J. Am. Chem. Soc., 2014, 136, 18111-18119.

12 J. G. Owen, Z. Charlop-Powers, A. G. Smith, M. A. Ternei, P. Y. Calle, B. V. B. Reddy, D. Montiel and S. F. Brady, Proc. Natl. Acad. Sci. U. S. A., 2015, 112, 4221-4226.

13 B. M. Hover, S. H. Kim, M. Katz, Z. Charlop-Powers, J. G. Owen, M. A. Ternei, J. Maniko, A. B. Estrela, H. Molina, S. Park, D. S. Perlin and S. F. Brady, Nat. Microbiol., 2018, 3, 415-422.

14 A. Bhushan, P. J. Egli, E. E. Peters, M. F. Freeman and J. Piel, Nat. Chem., 2019, 11, 931-939.

15 Y. Sugimoto, F. R. Camacho, S. Wang, P. Chankhamjon, A. Odabas, A. Biswas, P. D. Jeffrey and M. S. Donia, Science, 2019, 366, eaax917.

16 L. J. Stevenson, J. G. Owen and D. F. Ackerley, ACS Chem. Biol., 2019, 14, 2115-2126.

17 M. Katz, B. M. Hover and S. F. Brady, J. Ind. Microbiol. Biotechnol., 2016, 43, 129-141.

18 J. J. Zhang, X. Tang and B. S. Moore, Nat. Prod. Rep., 2019, 1313-1332.

19 H. S. Kang, J. Ind. Microbiol. Biotechnol., 2017, 44, 285-293.

20 H. S. Kang and S. F. Brady, Angew. Chem., Int. Ed., 2013, 52, 11063-11067.
21 S. F. Brady, Nat. Protoc., 2007, 2, 1297-1305.

22 R. Winn and M. Norris, Techniques in Aquatic Toxicology, CRC Press, vol. 2, 2010.

23 M. Metsä-Ketelä, V. Salo, L. Halo, A. Hautala, J. Hakala, P. Mäntsälä and K. Ylihonko, FEMS Microbiol. Lett., 1999, 180, 1-6.

24 S. Nurk, A. Bankevich, D. Antipov, A. A. Gurevich, A. Korobeynikov, A. Lapidus, A. D. Prjibelski, A. Pyshkin, A. Sirotkin, Y. Sirotkin, R. Stepanauskas, S. R. Clingenpeel, T. Woyke, J. S. Mclean, R. Lasken, G. Tesler, M. A. Alekseyev and P. A. Pevzner, J. Comput. Biol., 2013, 20, 714-737.

25 K. Blin, T. Wolf, M. G. Chevrette, X. Lu, C. J. Schwalen, S. A. Kautsar, H. G. Suarez Duran, E. L. C. De Los Santos, H. U. Kim, M. Nave, J. S. Dickschat, D. A. Mitchell, E. Shelest, R. Breitling, E. Takano, S. Y. Lee, T. Weber and M. H. Medema, Nucleic Acids Res., 2017, 45, W36-W41.

26 J. Garcia-Bernardo, A. F. Braña, C. Méndez and J. A. Salas, FEMS Microbiol. Lett., 2000, 186, 61-65.

27 E. Fernández, F. Lombó, C. Méndez and J. A. Salas, Mol. Gen. Genet., 1996, 251, 692-698.

28 N. Menéndez, A. F. Braña, J. A. Salas and C. Méndez, Microbiology, 2007, 153, 3061-3070.

29 J. H. Kim, Z. Feng, J. D. Bauer, D. Kallifidas, P. Y. Calle and S. F. Brady, Biopolymers, 2010, 93, 833-844.

30 D. Kallifidas and S. F. Brady, Methods in Enzymology, Academic Press, 2012, vol. 517, pp. 225-239.

31 S.-H. Leem, V. N. Noskov, J. Park, S. Il Kim, V. Larionov and N. Kouprina, Nucleic Acids Res., 2003, 31, 29.

32 H. S. Kang, Z. Charlop-Powers and S. F. Brady, ACS Synth. Biol., 2016, 5, 1002-1010.

33 M. G. Brazhnikova, E. B. Krugliak, I. N. Kovsharova, N. V. Konstantinova and V. V. Proshilakova, Antibiotiki, 1962, 7, 39-44.

34 H. Jayasuriya, R. B. Lingham, P. Graham, D. Quamina, L. Herranz, O. Genilloud, M. Gagliardi, R. Danzeisen, J. E. Tomassini, D. L. Zink, Z. Guan and S. B. Singh, J. Nat. Prod., 2002, 65, 1091-1095.

35 H. Ogawa, Y. Yamashita, R. Katahira, S. Chiba, T. Iwasaki, T. Ashizawa and H. Nakano, J. Antibiot., 1998, 51, 261-266.

36 Y. A. Berlin, M. N. Kolosov, I. V. Vasina and I. V. Yartseva, Chem. Commun., 1968, 762-763.

37 S. E. Wohlert, E. Künzel, R. Machinek, C. Méndez, J. A. Salas and J. Rohr, J. Nat. Prod., 1999, 62, 119-121.

38 K. Stajner, M. Blumauerová, D. A. S. Callieri and Z. Vaněk, Folia Microbiol., 1974, 19, 498-506.

39 Y. A. Berlin, M. N. Kolosov and I. V. Severtsova, Chem. Nat. Compd., 1975, 9, 492-497.

40 L. Prado, E. Fernández, U. Weißbach, G. Blanco, L. M. Quirós, A. F. Braña, C. Méndez, J. Rohr and J. A. Salas, Chem. Biol., 1999, 6, 19-30.

41 Y. A. Berlin, M. N. Kolosov and I. V. Yartseva, Chem. Nat. Compd., 1973, 9, 504-508.

42 D. Rodríguez, L. M. Quirós, A. F. Braña and J. A. Salas, J. Bacteriol., 2003, 185, 3962-3965.

43 M. Gibson, M. Nur-E-Alam, F. Lipata, M. A. Oliveira and J. Rohr, J. Am. Chem. Soc., 2005, 127, 17594-17595. 
44 S. Herai, Y. Hashimoto, H. Higashibata, H. Maseda, H. Ikeda, S. Omura and M. Kobayashi, Proc. Natl. Acad. Sci. U. S. A., 2004, 101, 14031-14035.

45 M. C. Kim, H. Machado, K. H. Jang, L. Trzoss, P. R. Jensen and W. Fenical, J. Am. Chem. Soc., 2018, 140, 10775-10784.

46 B. Langmead and S. L. Salzberg, Nat. Methods, 2012, 9, 357-359.

47 A. M. Bolger, M. Lohse and B. Usadel, Bioinformatics, 2014, 30, 2114-2120.
48 G. R. Fulmer, A. J. M. Miller, N. H. Sherden, H. E. Gottlieb, A. Nudelman, B. M. Stoltz, J. E. Bercaw and K. I. Goldberg, Organometallics, 2010, 29, 2176-2179.

49 I. Wiegand, K. Hilpert and R. E. W. Hancock, Nat. Protoc., 2008, 3, 163-175.

50 J. N. Copp, E. M. Williams, M. H. Rich, A. V. Patterson, J. B. Smaill, D. F. Ackerley and D. Ollis, Protein Eng., Des. Sel., 2014, 27, 399-403. 